\title{
DEROGACIÓN, RECHAZO Y SISTEMA JURÍDICO
}

\section{Introducción}

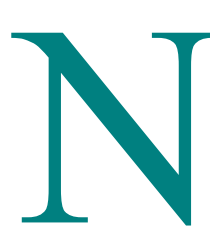

o supone ninguna novedad afirmar que la obra de C. Alchourrón y E. Bulygin constituye uno de los hitos capitales de la teoría del Derecho contemporánea; que ella ha contribuido de manera sobresaliente a aclarar multitud de problemas lógicos y conceptuales; y que ha servido, entre otras muchas cosas, para consolidar una determinada manera de hacer teoría del Derecho y, por tanto, también, de entenderla. La evidencia de la relevancia de dicha obra es tal que hace superflua cualquier justificación de su estudio. En este trabajo me voy a ocupar de algunas contribuciones de C. Alchourrón y E. Bulygin a la teoría de la derogación.

En un artículo de 1981, titulado «Teoría y técnica de la legislación», E. Bulygin proponía una determinada sistematización de los problemas con que se enfrenta el legislador cuando trata de resolver de manera anticipada conflictos sociales por medio de la legislación. Dentro de los problemas que él denominaba «técnicos» distinguía los «lingüísticos», (ambigüedad y vaguedad) de los «lógicos». Y dentro de estos últimos, a su vez, separaba los problemas «sistemáticos» (tales como las contradicciones, las lagunas y las redundancias normativas) de los problemas «dinámicos» (relacionados con la promulgación y la derogación) ${ }^{1}$. Esta última distinción es interesante porque si se leen los distintos trabajos en los que C. Alchourrón y E. Bulygin se han ocupado de la derogación, es fácil observar que, a pesar de que puedan apreciarse de unos a otros cambios no siempre sólo de detalle, todos ellos la respetan. Ello es debido, en mi opinión, a que, aunque a veces varíe la terminología que

${ }^{1}$ Bulygin, E.: «Teoría y técnica de la legislación», en Alchourrón, C. y Bulygin, E.: Análisis lógico y Derecho, C.E.C., Madrid, 1991, págs. 411-413 y 423. 
utilizan, la concepción de las normas con la que operan o los problemas colaterales que abordan, siempre permanece inalterada una distinción que es fundamental para la comprensión de su obra en materia de derogación: me refiero a la distinción entre sistema jurídico (entendido como conjunto de normas que contiene todas las consecuencias lógicas) y orden jurídico (entendido como una secuencia de sistemas jurídicos) ${ }^{2}$. Pues bien, lo que aquí me propongo hacer es mostrar algunas insuficiencias del aparato conceptual utilizado por Alchourrón y Bulygin para dar cuenta del fenómeno derogatorio tal como opera en el Derecho y, en particular, mostrar que en su obra se produce una cierta superposición entre los planos sistemático y dinámico. Al final, dicha crítica pretende también abrir una brecha en la noción misma de sistema jurídico, entendido como conjunto de normas promulgadas y no derogadas. La estrategia argumentativa que voy a seguir es la siguiente: intentar mostrar que su teoría del Derecho olvida ciertos datos sobre cómo opera realmente el Derecho y no permite dar cuenta de manera adecuada de distinciones a las que los juristas acuden con cierta frecuencia y que, si bien debe reconocerse que no están del todo bien construidas, no son enteramente arbitrarias, sino que responden a ciertas necesidades reales.

Pero antes de entrar a exponer y criticar las contribuciones de Alchourrón y Bulygin a la teoría de la derogación, quiero mostrar los cuatro contextos en los que, en mi opinión, los juristas se refieren a la derogación:

A. Todo el mundo admite el uso de la expresión «derogación», o mejor de «disposición derogatoria» cuando se encuentra con disposiciones que prevén la derogación de otras disposiciones a las que mencionan, esto es, con disposiciones del tipo: «queda derogado el art. x de la ley y».

B. Se habla también de derogación o de «disposiciones derogatorias genéricas» para referirse a cláusulas derogatorias que no mencionan las disposiciones que pretenden derogar. Estas cláusulas suelen adoptar formulaciones semejantes a la siguiente: «quedan derogadas todas las disposiciones que se opongan a lo dispuesto en la presente ley».

C. Los juristas recurren también a la expresión derogación cuando, en fase de interpretación y aplicación del Derecho, determinan las relaciones de preferencia entre normas jurídicas incompatibles. Así, por ejemplo, hablan de principios derogatorios para referirse a los criterios que gobiernan dicha ordenación, esto es, para referirse a los principios de lex superior, lex posterior y lex specialis ${ }^{3}$.

${ }^{2}$ Alchourrón, C. y Bulygin, E: «Sobre el concepto de orden jurídico», en Alchourrón, C. y Bulygin, E: Análisis..., ob. cit., pág 396 y 397.

${ }^{3}$ Más adelante argumentaré sobre la inconveniencia de considerar que todos estos principios están relacionados con la derogación. 
D. Finalmente, se utiliza también la expresión «derogación» para referirse a la sustitución de textos normativos aunque no cambie la disciplina de la materia por ellos regulada. Este es el caso, por ejemplo, de los llamados textos refundidos.

Si se analizan brevemente estos cuatro $\operatorname{casos}^{4}$, no es difícil observar que pueden reducirse a dos: los casos A y C, que los podríamos llamar respectivamente el caso de «la cláusula derogatoria concreta» y el caso de la «derogación por incompatibilidad». El caso $\mathrm{B}$, esto es, el de «las cláusulas derogatorias genéricas», puede ser reducido al $\mathrm{C}$ por la sencilla razón de que, como se han encargado de mostrar los estudios de técnica legislativa, dichas cláusulas derogatorias genéricas no aportan nada y son redundantes en relación con el principio de lex posterior ${ }^{5}$. Y, finalmente, el caso D es irrelevante para nuestros fines porque o bien se realiza incorporando cláusulas derogatorias concretas (en cuyo caso sería reducible al caso A), o bien lo único que genera es redundancia y éste es un problema menor del que aquí podemos prescindir.

\section{Promulgación, derogación e indeterminación lógica del sistema.}

La cuestión central que abordan C. Alchourrón y E. Bulygin en torno a lo que, siguiendo el esquema propuesto por Bulygin, podemos llamar problemas dinámicos es que los sistemas jurídicos pueden cambiar como resultado bien de la adición de nuevas normas (mediante actos de promulgación), bien de la sustracción de normas (mediante actos de derogación). Adición y sustracción son, según estos autores, las dos operaciones básicas a considerar.

¿Qué ocurre cuando se promulga una nueva norma? Se agrega la nueva norma al sistema anterior produciéndose así un cambio de sistema. Pero como, según la concepción de Alchourrón y Bulygin, el sistema jurídico está compuesto no sólo por las normas formuladas, sino también por las que de ellas se derivan, el sistema resultante

${ }^{4}$ Estos cuatro contextos de la derogación están directamente inspirados en la clasificación que hace R. Guastini de los actos derogatorios. Este autor distingue los actos derogatorios expresos de los tácitos. Dentro de los actos derogatorios expresos diferencia, a su vez, la derogación nominata de la derogación innominata; y dentro de los tácitos la derogación por incompatibilidad de la derogación por nueva disciplina. Cfr. Guastini, Riccardo: «In tema di abrogazione», en Luzzati, Claudio (a cura di): L'abrogazione delle leggi. Un dibattito analitíco, Giuffré, Milán, 1987, págs. 7 y ss. También puede verse Guastini, R: Dalle fonti alle norme, Giappichelli, Torino, 1990, págs. 245 y ss.

${ }^{5}$ Cfr. Aguiló Regia, Josep: Técnica legislativa y documentación automática de legislación, en «Informatica e diritto», enero-abril, 1990, págs. 105 y ss. 
contendrá las consecuencias de la base del sistema anterior (esto es, las consecuencias de sus normas formuladas), las consecuencias de la nueva norma y las consecuencias de la suma de ambas. El resultado de añadir una norma a un sistema jurídico es siempre -dicen Alchourrón y Bulygin- un sistema jurídico determinado, esto es, el resultado de esta operación es siempre unívoco ${ }^{6}$.

¿Qué ocurre cuando se deroga una norma? En el caso de la derogación las cosas son más complicadas. Aquí hay que distinguir tres supuestos distintos que, en opinión de Alchourrón y Bulygin, comportan dos conceptos diferentes de derogación, según que ésta conlleve o no un cambio de sistema: A. Derogación de la formulación de una norma sin que por ello se aniquile ninguna norma del sistema; B. derogación de una norma formulada; y C. derogación de una norma derivada?

A. Derogación de la formulación de una norma. Cuando en un sistema jurídico una norma ha sido formulada dos veces o cuando se formula una norma que ya existía en el sistema como norma derivada, entonces el sistema es redundante respecto de esa norma. Si se deroga la formulación de una norma redundante, se modifica la base del sistema. Sin embargo, el sistema permanece invariable, ya que contiene las mismas consecuencias ${ }^{8}$. Interesa aquí llamar la atención sobre lo siguiente: la derogación de la formulación de una norma redundante sólo puede llevarse a cabo a través de lo que antes hemos llamado cláusulas derogatorias concretas. Es decir, la única manera de eliminar la redundancia es mencionando la norma formulada que se quiere eliminar. La derogación por incompatibilidad necesariamente conlleva un cambio en las consecuencias del sistema jurídico.

B. Derogación de una norma formulada. Cuando se deroga una norma formulada para, eventualmente, colocar otra en su lugar, lo que se sustrae es la norma formulada, las consecuencias que de ella se derivan y todas las normas para cuya derivación ella era necesaria. Al igual que ocurría en el caso de la promulgación, el resultado de estas operaciones de sustracción es siempre unívoco, es decir, es un determinado sistema jurídico ${ }^{9}$. Aquí, a la luz de lo visto en la Introducción, la derogación podría llevarse a cabo bien mediante cláusulas derogatorias concretas, bien introduciendo una norma incompatible con la que se desea derogar. Ello, sin embargo, requiere algunos comentarios. En primer lugar, y como trataré de mostrar más adelante, la derogación por

${ }^{6}$ Alchourrón, C. y Bulygin, E.: «Sobre el concepto...» ob. cit. págs. 398 y 399.

${ }^{7}$ Ibidem, págs. 399 y 401.

${ }^{8}$ Ibidem, pág. 399.

${ }^{9}$ Ibidem, págs. 400 y 401. 
incompatibilidad, en mi opinión, sólo puede ser abordada desde la perspectiva de los conflictos entre normas, y estos conflictos, como hemos visto, eran señalados por Bulygin como típicos problemas sistemáticos. En segundo lugar, si la derogación se produce como consecuencia de una cláusula derogatoria concreta, entonces no hay diferencia sustancial entre este caso y el anterior, pues dichas cláusulas sólo pueden referirse a formulaciones de normas. En ambos casos lo que hace la autoridad es eliminar la formulación de una norma, aunque eventualmente puedan variar las consecuencias de la nueva base. Ello es importante porque, a diferencia de lo que sostienen Alchourrón y Bulygin ${ }^{10}$, lo que nos permite distinguir los dos conceptos relevantes de derogación no es el hecho contingente de que cambie o no el sistema, sino el de que hay dos operaciones distintas, que tienen lugar en niveles diferentes del lenguaje. Una consiste en dictar disposiciones que mencionan formulaciones de normas que deben ser eliminadas de la base del sistema. La otra, en introducir normas incompatibles con normas anteriores. Esa es, en mi opinión, la distinción conceptualmente relevante para la teoría de la derogación.

C. Derogación de una norma derivada. La cuestión se complica considerablemente cuando se trata de la derogación de una norma derivada, pues el resultado ya no es siempre unívoco, esto es, no es siempre un único conjunto de normas sino que puede ser una pluralidad alternativa de conjuntos de normas. Ello puede suceder cuando la norma derogada no sea consecuencia de ninguna norma en particular, pero si de un conjunto de normas. Con la eliminación de una de las normas pertenecientes a ese conjunto se solventa la cuestión, pero el problema radica en determinar de cuál de esas normas hay que desprenderse. Ello, que se ha convenido en llamar la paradoja de la derogación, supone, pues, la aparición del problema de la indeterminación lógica del sistema ${ }^{11}$. Alchourrón y Bulygin dicen que esta situación puede darse cada vez que el legislador emplea una cláusula derogatoria genérica sin especificar las normas que deroga ${ }^{12}$. Pero como ya he dicho anteriormente, estas cláusulas son redundantes con el principio de lex posterior, lo que quiere decir que el mismo problema puede presentarse con o sin cláusula derogatoria genérica. En cualquier caso, lo que sí es claro es que, al no conocerse cláusulas derogatorias concretas destinadas a derogar normas no formuladas, el único procedimiento posible es el de la derogación por incompatibilidad.

${ }^{10}$ Ibidem, pág. 401.

${ }^{11}$ Ibidem, págs 401-404. Sobre la indeterminación lógica del sistema normativo puede verse, también, Alchourrón, C. y Bulygin, E.: «La concepción expresiva de las normas», en Alchourrón, C. y Bulygin, E.: Análisis..., ob. cit., págs. 140 y 141.

${ }^{12}$ Alchourrón, C. y Bulygin, E: «Sobre el concepto...», ob. cit., pág. 403. 
Pero detengámonos por un momento en la derogación de normas no formuladas y veamos un ejemplo de paradoja de la derogación que Bulygin toma de Hilpinen ${ }^{13}$. Consideremos un sistema compuesto por las dos siguientes normas:

Q1: Juan debe trabajar todos los días de la semana entre las 10 y las $18 \mathrm{~h}$.

Q2: Juan no debe tomar alcohol mientras trabaja.

Supongamos ahora que con posterioridad el empleador de Juan dicta el siguiente permiso:

M: Juan puede tomar alcohol los sábados entre las 10 y las 18 horas.

Parece, en principio, que M levanta algunas prohibiciones existentes en el sistema anterior y que, dado que $\mathrm{M}$ es posterior, toda la cuestión puede resolverse aplicando el criterio de lex posterior. El problema, sin embargo, subsiste porque $\mathrm{M}$ es compatible con cada una de las normas formuladas de nuestro sistema pero, y ahí esta el quid, es incompatible con la conjunción de Q1 y Q2. O Q1 o Q2 debe ser eliminada, pero ¿cuál? La indeterminación consiste en que, al no disponer de un criterio para elegir entre las normas en cuestión, el resultado es una pluralidad alternativa de sistemas. En mi opinión, y no perdiendo de vista nuestro ejemplo, todo el problema radica exclusivamente en la pretensión de abordar la cuestión de la compatibilidad o incompatibilidad de esas tres normas desde la perspectiva de la derogación. Más adelante trataré de argumentar la inconveniencia de suponer que todos los conflictos entre normas que se producen por la introducción de una nueva norma en el sistema se resuelven por (o tienen que ver con la) derogación: sólo cabe considerar que media derogación cuando en la resolución del conflicto lo determinante es la ordenación temporal de las normas. En nuestro ejemplo, me parece claro que un jurista que se propusiera resolver el conflicto lo haría acudiendo a recursos interpretativos ajenos a la ordenación temporal. Creo que la mejor manera de ver que el caso representado por el ejemplo no debería ser visto como un caso de derogación u ordenación temporal radica en observar que nuestro jurista se encontraría exactamente con el mismo problema si las tres normas hubieran sido dictadas simultáneamente. Si es cierto que en ambos casos el jurista resolvería el caso acudiendo a criterios al margen del momento de la promulgación de las normas, parece razonable independizarlo de la derogación.

${ }^{13}$ Bulygin, E.: «Dogmática jurídica y sistematización del Derecho», en Alchourrón, C. y Bulygin, E.: Análisis..., ob. cit., pág. 474. 


\section{Rechazo, ambivalencia y derogación.}

Hasta ahora me he centrado básicamente en un artículo de 1970 titulado «Sobre el concepto de orden jurídico». En «La concepción expresiva de las normas» de 1981, Alchourrón y Bulygin introducen, entre otras muchas nociones, la de rechazo (o acto de rechazo) y, relacionada con ella, la de conflicto de ambivalencia. El rechazo -dicen- es el acto mediante el cual la autoridad identifica las normas que no quiere que formen parte del sistema normativo. Así, y ello tiene que ver con la concepción de las normas con que operan Alchourrón y Bulygin en el mencionado artículo, junto a la actitud de promulgar (que permite incrementar el conjunto de proposiciones ordenadas) hay que considerar la actitud de rechazar (que permite sustraer normas del sistema y también, como se verá más adelante, impedir su incorporación al mismo). Cuando los juristas hablan de derogación se están refiriendo, según nuestros autores, al rechazo de un contenido normativo. Hay que tener en cuenta que rechazar no es negar: el que rechaza una proposición no afirma ninguna proposición, mientras que el que niega una proposición sí. La diferencia que hay entre el rechazo y la negación puede verse a partir de considerar la diferencia que hay entre el agnóstico y el ateo. El primero rechaza la proposición de que «dios existe» sin afirmar nada, el ateo niega la verdad de dicha proposición afirmando la verdad de que «dios no existe» ${ }^{14}$.

Naturalmente, si hay dos actitudes normativas, la de promulgar y la de rechazar, tiene sentido hablar de conflictos entre promulgación y rechazo. La orden de hacer p y la orden de hacer $-p$ son conflictivas porque sus contenidos normativos $p$ y $-p$ son contradictorios: es imposible lógicamente satisfacer las dos órdenes. Si un mismo sistema contiene ambas órdenes entonces es incoherente, ya que contiene una contradicción. En forma semejante, la promulgación de una norma y el rechazo de la misma son incompatibles: cabe hablar de conflicto entre la promulgación o la orden de $\mathrm{p}$ y el rechazo de $\mathrm{p}$. Pero este conflicto es distinto del anterior. En el primero había acuerdo de actitudes (se trataba siempre de ordenar) y desacuerdo en el contenido normativo ( $\mathrm{p}$ y $-\mathrm{p}$ ). Alchourrón y Bulygin llaman a este tipo de conflicto incoherencia normativa. En el segundo, lo que se produce es un desacuerdo de actitudes (promulgar frente a rechazar) y un acuerdo en los contenidos normativos (se trata siempre de p). A este segundo tipo de conflicto, Alchourrón y Bulygin lo denominan ambivalencia ${ }^{15}$. $131-133$.

${ }^{14}$ Alchourrón, C. Bulygin, E.: «La concepción expresiva de las normas», ob. cit., págs.

${ }^{15}$ Ibidem, págs. 135 y 136. 
Según estos autores, en la práctica los juristas utilizan tres criterios o reglas de preferencia para resolver los conflictos entre actos de promulgación y de rechazo que se refieren al mismo contenido normativo. Estos tres criterios, que sirven para determinar qué acto debe prevalecer, son los de auctoritas superior, auctoritas posterior y auctoritas specialis. Estas reglas son distintas de (y no deben ser confundidas con) las de lex superior, lex posterior y lex specialis, que se utilizan para resolver los casos de incoherencia normativa ${ }^{16}$.

El criterio de auctoritas superior establece que debe prevalecer el acto (ya sea de promulgación o rechazo) realizado por la autoridad de nivel jerárquico superior. Esto es, si una autoridad superior promulga una norma, entonces esa norma no puede ser derogada por una autoridad inferior, o, en otras palabras, el sistema no cambia como consecuencia del acto realizado por la autoridad inferior. En definitiva, el rechazo de un contenido normativo realizado por una autoridad superior lleva a la eliminación del mismo, si éste había sido promulgado con anterioridad, e impide su futura adición al sistema mediante actos de promulgación realizados por autoridades inferiores. Este último caso muestra -dicen- que el rechazo no tiene por qué ser temporalmente posterior al acto de promulgación. Es decir, según Alchourrón y Bulygin, cabe hablar de derogación anticipada de normas todavía no promulgadas. Para darse cuenta de que ello tiene perfecto sentido basta -dicen- distinguir entre la operación de eliminación de los contenidos normativos que han sido rechazados y el acto de rechazo mismo. El rechazo de normas no promulgadas cumple la función de prevenir su promulgación y ello es lo que ocurre, por ejemplo, con los derechos y garantías constitucionales: previenen que ciertos contenidos normativos puedan ser agregados al sistema $^{17}$.

La regla de auctoritas posterior, que es suplementaria en relación con la de auctoritas superior, determina que el acto (ya sea de promulgación o rechazo) realizado con posterioridad prevalece sobre el anterior. Y la regla de auctoritas specialis implica que debe prevalecer el acto de contenido normativo menos general ${ }^{18}$.

Expuesto lo anterior, no quiero entrar a discutir hasta qué punto es preferible o no la concepción expresiva de las normas frente a la hilética, pero sí quiero entrar a valorar hasta qué punto la noción de rechazo es interesante para la teoría de la derogación. Para ello voy a distinguir los dos casos siguientes: A. el rechazo de normas que pertenecen al sistema y B. el rechazo de normas que no pertenecen al sistema.

\footnotetext{
${ }^{16}$ Ibidem, págs. 136 y 137.

${ }^{17}$ Ibidem, págs. 136 y 137.

${ }^{18}$ Ibidem, pág. 137.
} 
A. El rechazo de normas que pertenecen al sistema. En la Introducción he sostenido que la derogación de normas puede llevarse a cabo por dos procedimientos: bien mediante la edición de cláusulas derogatorias concretas, bien mediante la introducción en el sistema de normas incompatibles con las que se pretenden derogar. Pues bien, en mi opinión, la noción de rechazo sirve para explicar cómo opera la derogación a través de las cláusulas derogatorias concretas, pero no para dar cuenta de la derogación por incompatibilidad. Ello se debe a lo siguiente: si se interpreta -como hacen Alchourrón y Bulygin- que hay rechazo cada vez que el legislador se limita a regular de una manera diferente una determinada materia, entonces la noción de ambivalencia es sencillamente redundante con la de incoherencia normativa. El rechazo como acto de identificación, de las normas que la autoridad quiere que dejen de formar parte del sistema requiere la mención de las mismas. Cuando éstas no son mencionadas y lo único que ocurre es que se disciplina de una manera diferente una determinada materia, entonces sencillamente nos encontramos con un caso de incoherencia normativa como resultado de dos actos de promulgación. Lo que quiero decir con todo ello es que creo que la noción de rechazo, y como derivada de ella la de ambivalencia, puede valer para dar cuenta de lo que los juristas denominan «normas derogatorias», pues es claro que el conflicto que pueda darse entre la norma derogatoria (la cláusula derogatoria concreta) y la norma anteriormente promulgada que se pretende derogar es, en efecto, de naturaleza distinta a la incoherencia normativa. Esta forma de entender el rechazo no es, por cierto, otra cosa que reinterpretarlo de forma que no suponga una confusión entre los planos dinámico y sistemático $\mathrm{y}$, en el fondo, es el resultado de retomar la idea kelseniana de que entre la norma derogatoria y la norma que se deroga no se produce incoherencia normativa porque la norma derogatoria no incorpora un deber ser sino un no-deber-ser ${ }^{19}$.

Así entendido el rechazo, cabe hablar, por ejemplo, de conflicto entre la promulgación de la ley x y la derogación expresa o el rechazo de la ley x (si no se deroga expresamente no hay identificación de normas y, por tanto, no puede haber rechazo alguno). Lo que puedan aportar los criterios de auctoritas superior y auctoritas posterior a la solución de conflictos como éste es claro: Si una autoridad inferior dicta una cláusula derogatoria que dice, por ejemplo, que queda derogado el art. 25 de la constitución, prevalece, de acuerdo con el criterio de

${ }^{19}$ Cfr. Kelsen, H.: Teoría qenerale delle norme, ed. Mario G. Losano, trad. de Mirella Torre, Einaudi, Torino, 1985, pág. 171; o Kelsen, H: «Derogation», en Essays in leqal and Moral Philosophy, selección e introducción de O. Weinberger, Ed. Reidel, Dordrecht, 1973, pág. 261. 
auctoritas superior, la promulgación de la constitución frente al rechazo de la misma. Si el legislador dicta una cláusula derogatoria según la cual se deroga una ley anterior, en base al principio de auctoritas posterior, prevalece el rechazo de dicha ley frente a su promulgación. Lo que pueda aportar el criterio de auctoritas specialis ya no se entiende, pues según Alchourrón y Bulygin «estipula que un acto de promulgación o rechazo de un contenido normativo menos general prevalece sobre el acto referido a un contenido más general $»^{20}$. Y no se entiende por la sencilla razón de que, tal como hemos reinterpretado aquí el rechazo, éste requiere la mención de la norma que se rechaza y no puede haber conflicto entre los contenidos de las normas. Este conflicto puede darse como resultado de dos actos de promulgación (lo que podría dar lugar a una incoherencia normativa) pero no entre un acto de promulgación y otro de rechazo.

B. El rechazo de normas que no pertenecen al sistema. Es decir, aún no promulgadas. A propósito de ello escriben Alchourrón y Bulygin: «el rechazo no tiene porque ser temporalmente posterior al acto de promulgación [...] cabe hablar de «derogación» anticipada de normas todavía no promulgadas [...] Si distinguimos entre la operación de eliminación de los contenidos normativos que han sido rechazados y el acto de rechazo, nos daremos cuenta que tiene perfecto sentido rechazar un contenido normativo p, aun cuando p no pertenezca al sistema. [...] Esto es lo que ocurre con los derechos y las garantías constitucionales: la constitución rechaza por anticipado ciertos contenidos normativos (aquellos que afectan a derechos básicos), previendo su promulgación por el poder legislativo, pues si un contenido normativo tal es promulgado por el parlamento, puede ser declarado inconstitucional por los tribunales y no ser agregado al sistema ${ }^{21}$. En mi opinión, hablar de rechazo o derogación de normas aún no promulgadas sólo contribuye a confundir la derogación con la anulabilidad, instituciones que, por cierto, los juristas consiguen diferenciar con una facilidad que no parece ser compartida por los teóricos del Derecho, entre ellos, sin duda, Kelsen ${ }^{22}$ y, también, Alchourrón y Bulygin. En general, una norma será calificada como nula siempre por el hecho de que no se han satisfecho las condiciones estipuladas por alguna norma que confiere poderes o de que se ha vulnerado alguna norma que impone deberes relativos al

${ }^{20}$ Alchourrón, C. y Bulygin, E.: «La concepción expresiva de las normas», ob. cit., pág. 137.

${ }^{21}$ Ibidem, págs. 136 y 137.

${ }^{22}$ Para un análisis y crítica de la visión kelseniana de las relaciones entre derogación y anulabilidad, puede verse Aguiló Regla, J.: «La derogación de normas en la obra de Hans Kelsen», en Doxa no 10,1991 , págs. 223 y ss. 
ejercicio de esos poderes. Así, la nulidad de una norma será el resultado de que o bien la ha impuesto una autoridad a la que no se le había conferido el poder, o bien la autoridad ha utilizado un procedimiento distinto del previsto, o bien la autoridad ha vulnerado los límites de su poder al dictar una norma que entra en conflicto con normas superiores. Naturalmente, Alchourrón y Bulygin están en su derecho de afirmar que cada vez que se confiere un poder que no sea ilimitado (y probablemente la pretensión de conferir poder normativo ilimitado vulnere algún límite del lenguaje normativo) esta rechazando (y por tanto derogando por anticipado) todas las posibles normas que vulneren los límites de dicho poder, pero creo que con ello lo que hacen es, como ya he dicho, oscurecer la distinción entre derogación y anulabilidad. Y estas son instituciones distintas, que producen efectos diferentes y son llevadas a cabo por autoridades diferentes, pues quien rechaza o deroga es el legislador y quien declara la nulidad es la autoridad judicial. La derogación es un fenómeno perfectamente regular destinado a hacer posible el cambio normativo. Su función no es otra que la de evitar los inconvenientes que se derivarían de un orden jurídico estático. Por el contrario, la declaración de nulidad es siempre el resultado de reconocer que se ha producido un «cambio» normativo irregular. Su función no es la de posibilitar el cambio normativo, sino la de conservar el sistema. En mi opinión, esta distinción aparece desdibujada en Alchourrón y Bulygin porque, al haber caracterizado la validez de las normas como mera pertenencia al sistema y haber tomado como núcleo de la dinámica jurídica las operaciones de agregación y sustracción de normas, la norma derogada y la norma nula tienen en común que no pertenecen al sistema.

\section{Incoherencia normativa y derogación.}

De entre los distintos problemas sistemáticos a los que se han referido Alchourrón y Bulygin, me voy a centrar en el de las contradicciones entre normas. La idea básica de la que parten es que, dado que el contenido de los sistemas jurídicos depende de ciertos hechos empíricos, esto es, de los actos de promulgación y de derogación, no se puede excluir ni es de extrañar la posibilidad de que se den conflictos entre normas. En este sentido, afirman que los sistemas jurídicos no son meros conjuntos de normas, sino estructuras jerarquizadas. Tales jerarquías hacen posible que se dé preferencia a ciertas normas sobre otras. Es en este contexto en el que se refieren a los criterios de lex posterior, lex superior y lex specialis como criterios ordenadores. Así, afirman que la idea tan extendida de que la derogación es algo más fundamental y estable que la ordenación jerárquica ${ }^{23}$ es un error porque «en realidad 
ambos procedimientos son sustancialmente equivalentes. Aquellos contenidos normativos que 'son dejados de lado' al ser preferidos otros de mayor jerarquía son tan inaplicables (mientras no se modifique el orden jerárquico) como si estuvieran derogados» ${ }^{24}$. El problema que veo aquí es semejante al que se planteaba en el punto anterior y es el siguiente: tras la noción de ordenación jerárquica y su comparación con la derogación, Alchourrón y Bulygin están ocultando de nuevo algunas diferencias fundamentales en el Derecho. No me cabe la menor duda de que la ordenación realizada en base al principio de lex posterior es semejante y tiene consecuencias idénticas a las de la derogación. Pero, como ya apuntaba antes, la ordenación realizada en base al principio de lex superior no se parece a la derogación, porque de su aplicación no se sigue nada parecido a la derogación, sino la declaración de nulidad de la norma inferior. Respecto a la ordenación en base al criterio de lex specialis podría decirse algo semejante: no tiene sentido verlo como un principio derogatorio porque de él no se sigue derogación alguna. Básicamente este principio opera como un criterio de individualización de disposiciones jurídicas. Si ambas normas fueron dictadas simultáneamente entonces por aplicación de este principio no se produce ninguna modificación del dominio de validez de ninguna de las dos normas en conflicto. Y si fueron promulgadas en momentos diferentes y se produce modificación del dominio de validez de alguna de las dos normas, tal cosa sucede en virtud de lex posterior y no en virtud de lex specialis $^{25}$.

En definitiva, sólo la ordenación en base al criterio de lex posterior puede ser equiparada a la derogación expresa realizada por el legislador, pues sólo ella produce efectos semejantes a los de ésta. Al comienzo de este trabajo sostuve que había dos procedimientos derogatorios: Aquel llevado a cabo directamente por el legislador a través de las cláusulas

\footnotetext{
${ }^{23}$ En este punto conviene aclarar que hablar de derogación por incompatibilidad u ordenación de las normas en conflicto es una cuestión puramente terminológica, pues ambas expresiones se refieren a lo mismo. Conviene, sin embargo, hacer algunas matizaciones. Primera: mientras que la expresión «derogación por incompatibilidad» pone el acento en lo que es la actividad de la autoridad edictora de normas, la expresión «ordenación» tiende a resaltar el papel del intérprete o aplicador del Derecho. Segunda: desde la visión asumida en este trabajo, la expresión «ordenación de normas»es más amplia que la de «derogación por incompatibilidad», pues hay ordenaciones -aquellas que no tienen que ver con el momento de la promulgación de las normas en conflicto que no se consideran derogaciones por incompatibilidad.

${ }^{24}$ Alchourrón, C. y Bulygin, E.: «La concepción expresiva de las normas», ob. cit., pág. 145.

${ }^{25}$ Sobre ello puede verse Aguiló Regla, J.: «La derogación de normas en la obra de H. Kelsen», ob. cit., págs. 239 y 252 y ss.
} 
derogatorias concretas y que excluye cualquier deliberación por parte del aplicador del Derecho más allá de la resolución del conflicto entre el acto de promulgación y el de rechazo. Y aquel otro que requiere la intervención del aplicador del Derecho a través de la ordenación temporal de las normas ${ }^{26}$. Pues bien, sólo los conflictos de normas que se resuelven por aplicación de lex posterior puede considerarse que producen efectos derogatorios.

\section{Tiempo, validez y aplicabilidad.}

En «Tiempo y validez», de 1982, a partir de la idea de que los sistemas jurídicos cambian en virtud de actos de promulgación y derogación, E. Bulyginn ${ }^{27}$ analiza los aspectos temporales de las normas jurídicas. Dentro de los diferentes problemas allí abordados, me interesa aquí centrarme en las nociones de validez o existencia de una norma y de aplicabilidad de una norma.

Como ya sabemos, siempre que una nueva norma es agregada a un sistema jurídico tenemos un sistema diferente. Lo mismo ocurre con la derogación: cada vez que se sustrae una norma el resultado es un nuevo sistema jurídico. Así, el intervalo entre los dos momentos temporales en los cuales una norma es introducida y/o eliminada será lo que Bulygin llama tiempo externo de un sistema jurídico. La existencia de una norma (o validez o pertenencia a un sistema) puede ser caracterizada como la secuencia de todos los momentos externos en los cuales esa norma pertenece a algún sistema jurídico. Ello lleva a Bulygin a distinguir entre existencia en el sistema jurídico y existencia en el orden jurídico. Como consecuencia de todo ello, el tiempo externo de una norma será el intervalo que va desde el momento en que es promulgada hasta el momento en que es derogada. Frente a la idea de tiempo externo, el tiempo interno de una norma será la secuencia de todos los momentos temporales en los que la norma es aplicable a algún caso. Así, mientras el tiempo externo es una función de su pertenencia al sistema, el tiempo interno es una función de su aplicabilidad $^{28}$.

${ }^{26}$ Los sistemas automáticos de documentación de legislación son una buena muestra del distinto papel que juega el intérprete o aplicador del Derecho en uno y otro caso de derogación. Así, de acuerdo con lo aceptado, mientras que, cuando el legislador deroga expresamente, los responsables del sistema de documentación pueden realizar (y de hecho lo hacen) las operaciones de sustitución de unos textos por otros; en el caso de la derogación por incompatibilidad no pueden realizar operación alguna, pues se considera que su intervención resultaría siempre manipuladora, limitadora del papel del intérprete o aplicador del Derecho. Sobre esta cuestión puede verse Aguiló Regla, J.: «Técnica legislativa y documentación automática de legislación», ob. cit., págs. 99 v ss.

27 Bulygin, E.: «Tiempo y validez» en Alchourrón, C. y Bulygin, E.: Análisis..., ob. cit., págs. 195 y ss.

${ }^{28}$ Ibidem, págs. 198 y 199. 
Dentro de este contexto, la pregunta que se impone es qué efectos produce la derogación de una norma. La respuesta de Bulygin será que la norma derogada deja de existir pues ya no pertenece a los sistemas subsiguientes. Ello, reconoce el propio Bulygin, lleva a resultados un tanto sorprendentes dado que, como en multitud de ocasiones el tiempo externo y el interno no coinciden, un juez, en virtud de los criterios de aplicabilidad del sistema, deber aplicar normas que ya no existen. Pero ello, dirá Bulygin, no es tan extraño, pues si bien las normas en cuestión no existen en el sistema correspondiente al momento de la decisión, si existen en el orden jurídico ${ }^{29}$.

El propio Bulygin explora las posibilidades de una explicación alternativa. Esta consiste en hacer depender la existencia o pertenencia de una norma a un sistema de su aplicabilidad. Así, según esta explicación alternativa una norma aunque esté derogada seguirá existiendo, perteneciendo al sistema, mientras sea aplicable. Sólo cuando la norma derogada deje de tener aplicación alguna dejará de pertenecer al sistema. Las normas derogadas coexisten con las nuevas normas dentro del mismo sistema y, como son normalmente incompatibles, los posibles conflictos son evitados mediante la asignación de diferentes áreas de aplicabilidad. Se aplican a casos distintos. De esta forma, dice Bulygin, la existencia se convierte en una función de la aplicabilidad. Pero ello -añade Bulyginimplica que la existencia de una norma no comienza desde el momento de su promulgación, sino desde el momento de su aplicabilidad ${ }^{30}$.

A partir de ahí, propone algunos ejemplos con el fin de mostrar hasta qué punto esta forma de concebir la existencia de las normas lleva a tener que dar explicaciones más forzadas que la de reconocer que en ocasiones los jueces aplican normas que ya no existen. Los ejemplos a los que he aludido tienen que ver con la vacacio legis, los contratos que prevén el surgimiento de obligaciones en un momento posterior al de la firma y los testamentos que no producen efectos hasta la muerte del causante. En todos estos casos -dirá Bulygin- suena raro decir que esas normas -una ley, un contrato o un testamento- no existen hasta que no son susceptibles de producir efectos ${ }^{31}$. No me voy a detener aquí en ellos; sí deseo, sin embargo, contestar a un argumento que me parece importante.

Escribe Bulygin: «aun si se aceptara que una norma existe en el sistema mientras sea aplicable a algunos casos, no podemos concluir

\footnotetext{
${ }^{29}$ Ibidem, pág. 210.

${ }^{30}$ Ibidem, págs. 136 y 137.

${ }^{31}$ Ibidem.
} 
que se trata de la misma norma la que sigue existiendo después de la derogación. Si en t1 hay una norma aplicable a una cierta clase de casos (que incluye casos futuros) y en t2 esta norma ha sido derogada y ya no es más aplicable a los mismos casos (por ejemplo, no es aplicable a casos futuros) ¿sigue siendo la misma norma? Creo -sigue Bulygin- que sería correcto decir que no es la misma norma. La norma $\mathrm{N}$ ha sido reemplazada por la norma $\mathrm{N}$ ' que tiene el mismo contenido pero diferente ámbito de aplicabilidad y esto es suficiente para decir que son normas distintas. En efecto, si hay casos a los que una norma es aplicable y la otra no, las dos normas no son idénticas [...] Resulta entonces que después de todo con la derogación la norma queda eliminada del sistema $\rangle^{32}$.

No sé hasta qué punto es acertada esta descripción de Bulygin. En efecto, cuando Bulygin dice que la norma no derogada es aplicable a los casos futuros y que éstos caen dentro de su ámbito de aplicabilidad no creo que esté siendo muy fiel a la visión que todos tenemos de las normas jurídicas. Ello puede mostrarse a partir de considerar las dos situaciones siguientes. Primera: un ciudadano acude a un abogado en demanda de asesoramiento jurídico. El ciudadano en cuestión le dice al abogado que tiene pensado realizar un determinado acto la semana que viene. La consulta consiste, pues, en que el abogado le determine las consecuencias jurídicas que la realización de ese acto lleva aparejadas. La respuesta del abogado consiste en decirle que la norma $\mathrm{N}$, que pertenece al sistema presente, es aplicable al caso y que, por lo tanto, de su acción se derivarán tales consecuencias jurídicas. El ciudadano en cuestión saldrá del despacho del abogado convencido de que las normas no derogadas se aplican a casos futuros. Segunda situación: el mismo abogado recibe la visita de otro ciudadano que tiene pensado realizar la misma acción que el ciudadano anterior pero en lugar de la semana que viene piensa llevarla a cabo en el año 2030. La prudencia del abogado y su conocimiento de la naturaleza dinámica del Derecho le lleva, en este caso, a condicionar su respuesta y a decir que, en la medida en que no cambien las cosas, esto es, en la medida en que no se haya dictado otra norma que excluya la aplicabilidad de N, N será aplicable. Este segundo ciudadano saldrá del despacho del abogado con la impresión de que la aplicabilidad de las normas jurídicas a casos futuros está siempre condicionada a que no se dicten otras normas. ¿Qué muestra todo ello y cuál es la diferencia entre una y otra situación? Es claro que la expresión «casos futuros» incluye tanto a la semana que viene como al año 2030. La única diferencia entre una situación y otra

${ }^{32}$ Ibidem, págs. 212 y 213. 
es que en la primera la experiencia del abogado le demuestra que el Derecho ordinariamente no cambia sin «avisar» de una semana para otra. Pero ello no implica que el abogado no sepa que la aplicabilidad de las normas jurídicas a casos futuros está siempre condicionada. Si lo anterior es cierto, y esta forma de explicar la relación de las normas jurídicas con los casos futuros es acertada, uno puede huir del argumento de Bulygin y sostener que la derogación de una norma supone, en efecto, la limitación temporal de su aplicabilidad sin que ello le lleve a tener que afirmar que la norma derogada es distinta de ella misma antes de la derogación. La aplicabilidad de la norma antes de la derogación estaba sometida a condición, y la verificación de una condición nada tiene que ver con el cambio de la norma.

Finalmente quiero hacer una reflexión sobre la utilidad de la noción de sistema jurídico entendido como conjunto de normas promulgadas y no derogadas. Si se acepta esta idea, y en consecuencia se afirma, como hace Bulygin, que hay normas que no existen en el sistema pero que son aplicables, la noción de sistema puede ser perfectamente consistente pero también perfectamente distorsionadora a la hora de dar cuenta de los problemas con los que se enfrenta un jurista cuando resuelve un caso. Al jurista le interesa determinar el conjunto de normas aplicables a un caso, hayan sido derogadas o no, y sobre ellas resolver los problemas de contradicciones y lagunas. Ningún jurista se ha preocupado jamás -y parece que tiene sentido que no lo haya hecho- de determinar el conjunto de normas existentes en un momento t para resolver los conflictos y las lagunas que se den entre esas normas, sino que más bien le ha preocupado determinar el conjunto de normas aplicables a un caso y sobre ellas resolver los conflictos y las lagunas. Lo relevante para él es (y ha sido siempre) la aplicabilidad, no la «pertenencia».

\section{Algunas conclusiones provisionales a propósito de la derogación.}

1. El término «derogación» es ambiguo. Se utiliza para referirse a dos operaciones distintas, que tienen lugar en niveles distintos del lenguaje. Una, la derogación expresa, se realiza a través de las cláusulas derogatorias concretas; otra, la derogación por incompatibilidad, supone la edición de normas incompatibles con las que se derogan.

2. La derogación expresa opera siempre sobre formulaciones de normas (esto es, sobre los textos de las fuentes o, en la terminología de Alchourrón y Bulygin, sobre la base del sistema). Para que ella tenga lugar es condición necesaria la mención de las formulaciones de las normas que se pretenden derogar. La cuestión de si cambia o no el conjunto de soluciones normativas del sistema jurídico es un problema distinto: habrá derogaciones expresas que conlleven un cambio 
en dicho conjunto y otras que no. Lo que cambia necesariamente cada vez que hay una derogación expresa es el conjunto de normas formuladas.

3. Del hecho de que la derogación expresa opere siempre sobre la base del sistema se sigue que la realiza directamente la autoridad edictora que tiene competencia para intervenir sobre aquella. Para que se produzca la derogación expresa no se requiere la intervención del interprete o aplicador del Derecho. Este interpreta y, como consecuencia de ello, aplica las normas formuladas que le suministra la autoridad edictora.

4. No cabe hablar de incoherencia normativa como resultado de una derogación expresa. Entre la cláusula derogatoria concreta y la formulación de la norma que ella menciona no puede darse una contradicción, pues sus contenidos no pueden ser jamás conflictivos. El único conflicto que puede darse es entre el acto de promulgación de la norma que se pretende derogar y el acto de rechazo representado por la cláusula derogatoria concreta.

5. El efecto que tiene la derogación expresa es el de limitar en el tiempo la posibilidad de utilizar una determinada formulación de una norma (esto es un determinado texto de las fuentes) como fundamento para una determinada solución normativa.

6. La derogación por incompatibilidad opera no en el nivel de las formulaciones de normas, sino en el de los contenidos proposicionales de dichas formulaciones. Ello supone que siempre que tiene lugar una derogación por incompatibilidad se produce un cambio en el conjunto de soluciones normativas del sistema.

7. Para que la derogación por incompatibilidad tenga lugar es condición necesaria que la autoridad edictora de normas haya generado (a través de dos actos de promulgación) una incoherencia normativa. Otro elemento necesario de la derogación por incompatibilidad es la intervención del intérprete o aplicador del Derecho que debe realizar una ordenación (dar preferencia a unas sobre otras) de las normas conflictivas.

8. No toda incoherencia normativa da lugar a una derogación por incompatibilidad. Sólo hay derogación cuando la ordenación de las normas conflictivas se realiza aplicando el criterio de lex posterior.

9. Hablar de derogación anticipada de normas, esto es, de normas aún no promulgadas, es un artificio que sólo contribuye a confundir la derogación con la anulabilidad, instituciones diferentes que cumplen funciones diferentes, producen efectos diferentes y son llevadas a cabo por autoridades diferentes. La derogación de normas cumple la función de permitir el cambio regular del sistema jurídico (es el resultado de un 
cambio regular de voluntad normativa); en general, produce el efecto de limitar en el tiempo la aplicación de las normas derogadas, y es llevada a cabo por la autoridad edictora de normas. La declaración de nulidad cumple la función de impedir los cambios irregulares del sistema (es el resultado de preservar una determinada voluntad normativa); en general, produce el efecto de excluir totalmente la aplicabilidad de las normas declaradas nulas, y es llevada a cabo por la autoridad aplicadora del Derecho.

10. Que la derogación implique la limitación temporal de la aplicabilidad de una norma (esto es, que la norma en cuestión ya no sea aplicable a casos futuros) no supone que la norma derogada sea distinta de ella misma antes de la derogación. Dada la naturaleza dinámica del Derecho, la aplicabilidad de las normas jurídicas a casos futuros está siempre sometida a condición, y la verificación de una condición nada tiene que ver con el cambio de norma. 